\title{
Comparison of sprint interval and continuous endurance training on oxidative stress and antioxidant adaptations in young healthy adults
}

Authors' Contribution: A Study Design

B Data Collection

C Statistical Analysis

D Data Interpretation

E Manuscript Preparation

F Literature Search

G Funds Collection

\author{
Gulbin Rudarli Nalcakan ${ }^{1 \text { ABCEF }}$, Ece Onur ${ }^{2}$ ABCDE, Arzu Oran ${ }^{2}$ CDEF, S. Rana Varol ${ }^{1}$ ACDE \\ ${ }^{1}$ Ege University, Faculty of Sport Science, Department of Coaching Education, \\ Izmir, Turkey \\ ${ }^{2}$ Celal Bayar University, Faculty of Medicine, Department of Biochemistry, \\ Manisa, Turkey
}

Material and methods:

Results: Increases in GSH-Px ( $30 \%$ vs. $55 \%)$, TOS (33\% vs. $18 \%)$ and a significant decrease in MDA $(8.6 \%$, $\mathrm{p}<0.003 ; 6.8 \%, \mathrm{p}<0.016)$ in CET and SIT were observed, respectively. By contrast, TAS decreased (62\%) after CET and increased (17\%) after SIT. No significant differences in these parameters were reported after the training period between SIT and CET groups.

Conclusions: SIT was suggested as a safe exercise model to improve general health and the performance of traditional CET.

Key words: aerobic training, high-intensity interval, lipid peroxidation, total oxidant status, glutathione peroxidase.

\section{article details}

Article statistics: Word count: 2,939; Tables: 2; Figures: 0; References: 40

Received: October 2020; Accepted: February 2021; Published: June 2021

Full-text PDF: http://www.balticsportscience.com

Copyright

Indexation:

(c) Gdansk University of Physical Education and Sport, Poland

Celdes, Clarivate Analytics Emerging Sources Citation Index (ESCI), CNKI Scholar (China National Knowledge Infrastructure), CNPIEC, DOAJ, EBSCO - Central \& Eastern European Academic Source, EBSCO - SPORTDiscus, EBSCO Discovery Service, Google Scholar, Index Copernicus, J-Gate, Naviga (Softweco, Primo Central (ExLibris), ProQuest - Family Health, ProQuest - Health \& Medical Complete, ProQuest - Illustrata: Health Sciences, ProQuest Nursing \& Allied Health Source, Summon (Serials Solutions/ProQuest, TDOne (TDNet), Ulrich's Periodicals Directory/ ulrichsweb, WorldCat (OCLC)

Funding: This study was supported by the Ege University Scientific Research Projects Directorate (2014.besyo.004).

Conflict of interests: Corresponding author:

Open Access License:
Authors have declared that no competing interest exists

Gulbin RUDARLI NALCAKAN, Ege University Faculty of Sport Sciences, Bornova - Izmir - Turkey.

Phone no.: 009023234257 14, fax: 009023233990 00; e-mail: gulbinrn@gmail.com

This is an open access article distributed under the terms of the Creative Commons Attribution-Non-Commercial-NoDerivatives 4.0 International (https://creativecommons.org/licenses/by-nc-nd/4.0/), which permits use, distribution and reproduction in any medium, provided the original work is properly cited, the use is non-commercial and is otherwise in compliance with the license. 


\section{INTRODUCTION}

Aerobic exercise training induces numerous morphological and metabolic adaptations in skeletal muscle, including mitochondrial biogenesis and an enhanced capacity to oxidize fuels, such as glucose and fats [1]. These adaptations to continuous endurance training (CET) are linked with improved metabolic health and reduced risk for several metabolic diseases, such as obesity, insulin resistance, and type 2 diabetes [2-4].

Despite the proven positive effects of aerobic training on health, lack of time is the most common reason why many people fail to accomplish training programs [5, 6]. Low-volume, high-intensity interval training (HIT) has recently gained popularity as a time-efficient method of improving anaerobic and aerobic fitness [7] in only a few sessions in healthy people and also in patients with metabolic disorders $[5,8]$.

The most common model employed in low-volume HIIT studies has been the repeated Wingate test, which consists of a $30 \mathrm{~s}$ 'all-out' cycling effort against a supra-maximal workload. Wingate-based HIIT, which is known as sprint interval training (SIT), was typically performed for four to six work bouts separated by $\sim 4$ min of recovery, for a total of 2-3 minutes of intense exercise during a training session that lasts $\sim 20$ min with three sessions per week $[5,9,10]$. When compared on a matched-work basis or when estimated energy expenditure is equivalent, HIIT can serve as an effective alternative to traditional endurance training, inducing similar or even superior changes in a range of physiological, performance and health-related markers in both healthy individuals and diseased population [5, 9].

Exercise can increase the generation of reactive oxygen species (ROS), especially for single bouts of training, and elevated concentration of ROS causes oxidative damage of lipids, proteins, and DNA [11]. In fact, despite ROS having a fundamental role as signaling molecules in several determinant cellular pathways, redox changes induced by increased ROS production during exercise are negatively related to cellular homeostasis and might compromise the cellular function [12]. In skeletal muscle fibers, exercise-induced oxidative stress has been associated with fatigue, longer recovery time, and an increased injury rate [13].

The effectiveness of SIT training stems from high anaerobic demand, mainly in the first bouts, and increasing aerobic contribution with a higher number of sessions [14]. During repetitive high intensity effort, the oxidative metabolism causes an increase in the rate of oxygen transport due to workloads and fluctuations in oxygen uptake [15], while a decrease occurs in the ability to stimulate ATP production through the breakdown of phosphocreatine and glycogen [14]. Consequently, after repeated muscle contractions, oxidative stress can significantly reduce calcium intake by the sarcoplasmic reticulum and the ability to create action potentials that contribute to an acute decrease in performance during exercise [16].

Although during prolonged submaximal aerobic exercise, the increase in ROS production is mainly due to a disturbance in electron transport leading to increased leakage of superoxide radicals, oxidative stress specific to anaerobic exercise may be mediated through various other pathways, such as proton accumulation, due to lactic acidosis, auto-oxidation of catecholamine, catabolism of purines to xanthine and urate, and a transient and acute muscular deoxygenation, which resembles the ischemia-reperfusion syndrome [17].

Since excessive generation of ROS in unaccustomed muscles is harmful while the modest generation by regular exercise is beneficial to upregulating defense mechanisms against oxidative stress. It appears that chronic exercise training has a protective effect through 
the improvement in antioxidant capacity [12], thus forming a basis of hormetic effects of exercise [11]. Furthermore, anaerobic exercise training can induce adaptations that act to attenuate the exercise-induced oxidative stress. These may be specific to increased antioxidant defenses and may reduce the generation of pro-oxidants during and after exercise [18]. Although SIT has been shown to produce several positive health benefits, such as improved glycemic control and insulin sensitivity [19], cardiac function [20], blood lipid profile [21] and fat oxidation [22], scholarly data have been scarce regarding the effects of oxidative stress on short-term training [23]. Therefore, this study aimed to compare the effects of SIT and CET on oxidative stress and antioxidant indices in healthy young males. We hypothesized that similar oxidative stress and antioxidant adaptation would be observed in SIT and CET.

\section{MATERIAL AND METHODS}

\section{PARTICIPANTS}

Following medical history inquiries, physical examinations, and blood testing, 15 healthy young recreationally active university students who met the inclusion criteria (age: $21.7 \pm 2.2$ years, body mass index (BMI): $25.0 \pm 2.1 \mathrm{~kg} . \mathrm{m}^{-2}$, percentage of body fat (BF\%): $16.2 \pm 3.2 \%, \mathrm{VO}_{2} \max : 40.3 \pm 5 \mathrm{ml} . \mathrm{min}^{-1} . \mathrm{kg}^{-1}$ ) voluntarily participated in the study. The inclusion criteria were to be 20-26 years old; not being obese (BMI < 30), anemic, and actively infected; not having any health problems and injuries; not using alcohol, tobacco products, and drugs that affect lipid, lipoprotein and antioxidant metabolism; being habitually active but not engaged in any sort of structured training program for at least five months before the study. Moreover, participants were instructed not to perform any additional exercise, modify their regular daily diet regimen, and take any medications and supplements during the study period.

The study protocol was approved by the Local Scientific Research Ethics Committee (Approval No: 20.478.486-159). Participants were informed about the study procedures and associated risks and were asked to sign a written informed consent form.

\section{EXPERIMENTAL DESIGN}

A repeated measures study design was employed for this prospective laboratory experiment. All experimental procedures were performed in standard $20-22^{\circ} \mathrm{C}$ temperature and $50-$ $55 \%$ relative humidity condition. Before the training sessions, participants visited the laboratory to collect fasting blood samples and record anthropometric measurements. The following day, participants joined in a familiarization session to adapt to the testing/training procedures, the laboratory environment, and to meet with the study group. Following a submaximal test, a maximal graded exercise test and a verification phase were performed to determine the subjects' $\mathrm{VO}_{2}$ max levels. After the baseline measurements, subjects were matched according to their initial $\mathrm{VO}_{2}$ max levels and divided into two groups as follows (numbers indicate ranking of $\mathrm{VO}_{2}$ max values; $1=$ the highest, $15=$ the lowest) [24]:

$\begin{array}{lllllllll}\text { CET: } & 1 & 4 & 5 & 8 & 9 & 12 & 13 & \\ \text { SIT: } & 2 & 3 & 6 & 7 & 10 & 11 & 14 & 15\end{array}$

Sprint intervals and endurance training periods were continued for 7 weeks. At the end of the training period, the baseline tests were repeated in the same order. All procedures were performed on a mechanically braked cycle ergometer (894E, Monark, Sweden), which was set up to replicate the participants' normal riding position for all tests. 


\section{POCEDURES}

\section{Anthropometric measurements}

Height and body weight were measured with minimal clothing (Seca 767, Hamburg, Germany) using standard methods. The body fat ratio was measured on the body composition analysis device (Tanita MC 780MA, USA), which operates with the bioelectric impedance method.

\section{Determination of $\mathrm{VO}_{2} \max$}

Familiarization sessions consisted of a 20-min submaximal cycling and a 30-sec all-out sprint cycling bout that used the load of $10 \%$ of the body mass.

(1) A submaximal graded exercise test that consisted of four 5-min stages were performed to find subjects' respiratory anaerobic thresholds because maximal graded exercise tests were adjusted from the respiratory anaerobic threshold to exhaustion. (2) We focused on terminating the graded exercise tests approximately $10 \pm 2$ minutes. Test velocities were fixed at $60 \mathrm{rpm}$. Test loads were increased by $\sim 20$ watts at the $4 \mathrm{th}, 6 \mathrm{th}, 8 \mathrm{th}, 10 \mathrm{th}$, 11 th, and continued with one-minute intervals till volunteer exhaustion. Strong verbal encouragement, yet avoiding to give progress feedback, was given to the participants to reveal volitional exhaustion. Peak $\mathrm{VO}_{2}$ uptake was calculated as the highest value of $\mathrm{VO}_{2}$ observed over 30 seconds. (3) Following the maximal graded exercise test, a constant load verification phase was performed corresponding to the workload of peak $\mathrm{VO}_{2}$ revealed.

Oxygen uptake was measured breath-by-breath using a Cosmed Quark b2 with expired gas concentrations (Cosmed Srl, Rome, Italy). The device was calibrated according to the manufacturer's instructions. The turbine flow meter was calibrated using a 3-L syringe (Quinton Instruments, USA). HR data were collected with a telemetric system belonging to the same gas analyzer (Polar Electro OY, Kempele, Finland).

\section{Biochemical Measurements}

Fasting blood samples were drawn from an antecubital forearm vein between 08.00 and $10.00 \mathrm{am}$ by a nurse, and then centrifuged at $4000 \mathrm{rpm}$ for $10 \mathrm{~min}$. Plasma/sera were removed and kept at $-80^{\circ} \mathrm{C}$ until analysis. To minimize the influence of analytical variation, all samples were analyzed on the same day for each measurement. Within-batch CV's and internal controls of the lab for all the analyzed parameters were at an acceptable level.

The plasma malondialdehyde (MDA) level was determined via the spectrophotometrical method (Shimadzu UV-1201 V, Japan) described by Ohkawa et al. [25]. An external standard curve was prepared using 1,1,3,3-tetraethoxypropane. Results are given in the $\mu \mathrm{mol} / \mathrm{l}$ unit.

Plasma glutathione peroxidase (GSH-Px) activities were determined by the method of Paglia and Valentine [26]. Cumene hydroperoxide was added as a substrate. Oxidized glutathione produced by the action of GSH-Px present in the sample was then reduced by glutathione reductase in the presence of NADPH. The decrease in NADPH was recorded at $340 \mathrm{~nm}$ spectrophotometrically. Results are given in the $\mu \mathrm{mol} / \mathrm{l}$ unit.

Total antioxidant status (TAS) and total oxidant status (TOS) were determined with a commercial kit (Rel Assay Diagnostics, Turkey) spectrophotometrically by an autoanalyzer (Siemens Advia 1800, USA) using an automated colorimetric method developed by Erel $[27,28]$. The coefficient of variation (CV) of the kit was calculated as $10 \%$. The measuring range for serum TAS level was 0-2.75 mmol Trolox Eq/L, and for serum TOS the level was 0-33.5 $\mu \mathrm{mol} \mathrm{H}_{2} \mathrm{O}_{2} \mathrm{Eq} / \mathrm{L}$. 


\section{Training intervention}

The SIT regimen consisted of 4-6 Wingate all-out sprints with 4.5 min recoveries, while CET consisted of 30-50 min of cycling at a workload corresponding to $60 \%$ of $\mathrm{VO}_{2}$ max. SIT repetitions and CET durations were gradually increased every seven sessions throughout the training periods. Training sessions were performed three times a week for seven consecutive weeks. A rest of one to two days between training sessions was provided to allow enough recovery.

\section{STATISTICAL METHODS}

Descriptive statistics were reported as the mean \pm standard deviations. The Shapiro-Wilk $\mathrm{W}$ test showed that the data obtained met the assumptions of normality. Group (CET and SIT) was the between-subjects factor, and Time (0. Week and 7. Week) was the withinsubjects factor in the present study. The main effects and the interaction effect of these factors on the dependent variables were assessed using a $2 \times 2$ (Group $\times$ Time) twofactor mixed-design analysis of variance (ANOVA). These tests were also performed in case of insignificant overall mixed-design ANOVA results to identify the effect size (d) of the difference, which is an essential determinant of practical significance. Baseline values of dependent variables were compared between CET and SIT using an IndependentSamples T-Test. The Mann-Whitney U test was used to compare deltas (W1-W0) between the groups. The level of statistical significance was set at $\mathrm{p} \leq 0.05$.

\section{RESULTS}

Similar mean age, height, mass, body fat percentage, and $\mathrm{VO}_{2}$ max level of the SIT and CET groups are displayed in Table $1(\mathrm{p}>0.05)$.

Table 1. Physical and physiological characteristics of CET $(n=7)$ and SIT $(n=8)$ groups

\begin{tabular}{lccc} 
Parameters & CET & SIT & p value \\
\hline Age (year) & $21.3 \pm 2.36$ & $22.0 \pm 2.14$ & 0.549 \\
Height $(\mathrm{m})$ & $1.80 \pm 0.06$ & $1.84 \pm 0.01$ & 0.149 \\
Mass $(\mathrm{kg})$ & $79.3 \pm 6.69$ & $86.2 \pm 8.00$ & 0.098 \\
Body fat ratio (\%) & $15.8 \pm 2.62$ & $16.5 \pm 3.72$ & 0.668 \\
$\mathrm{VO}_{2}$ max $\left(\mathrm{ml} \cdot \mathrm{min}^{-1} \cdot \mathrm{kg}^{-1}\right)$ & $40.46 \pm 5.99$ & $40.16 \pm 4.26$ & 0.912 \\
\hline
\end{tabular}

Note: CET - continuous endurance training; SIT - sprint interval training; $\mathrm{VO}_{2} \mathrm{max}$ - maximal oxygen consumption.

No significant Group $\times$ Time interaction effect was found for any of the dependent variables, indicating that changes in these variables over the course of the study showed similar patterns in the CET and SIT groups: GPx $\left(\mathrm{F}[1,13]=0.064, \mathrm{p}=0.804, \mathrm{n}_{\mathrm{p}}{ }^{2}=0.005\right)$; MDA $\left(\mathrm{F}[1,13]=0.468, \mathrm{p}=0.506, \mathrm{n}_{\mathrm{p}}^{2}=0.035\right) ; \mathrm{TAS}\left(\mathrm{F}[1,13]=1.099, \mathrm{p}=313, \mathrm{n}_{\mathrm{p}}{ }^{2}=0.078\right) ;$ TOS $\left(\mathrm{F}[1,13]=0.299, \mathrm{p}=0.594, \mathrm{n}_{\mathrm{p}}^{2}=0.022\right)$.

After the training period, GSH-Px (30\%) and TOS (33\%) levels were increased while MDA $(8.6 \%, \mathrm{p}<0.003)$ and TAS (62\%) levels were decreased for CET. On the other hand, GSHPx (55\%), TOS (18\%), and TAS (17\%) levels were increased, while MDA (6.8\%, p < 0.016) was significantly decreased for SIT. There were no significant differences between CET and SIT in average values and percentage change in means $(\Delta \%)$ of oxidative stress and antioxidant results (Table 2). 
Table 2. Influence of CET and SIT on oxidative stress and antioxidant indices

\begin{tabular}{|c|c|c|c|c|c|c|c|c|c|c|}
\hline & \multicolumn{5}{|c|}{ CET $(n=7)$} & \multicolumn{5}{|c|}{ SIT $(n=8)$} \\
\hline & Week & $M \pm S D$ & $\Delta \%$ & $p$ & $d$ & Week & $M \pm S D$ & $\Delta \%$ & $p$ & $d$ \\
\hline \multirow{3}{*}{ 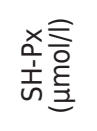 } & wo & $687.9 \pm 195.0$ & \multirow{3}{*}{30.3} & \multirow{3}{*}{0.229} & \multirow{3}{*}{-0.746} & wo & $601.1 \pm 211.6$ & \multirow{3}{*}{55.3} & \multirow{3}{*}{0.318} & \multirow{3}{*}{-0.576} \\
\hline & & & & & & & & & & \\
\hline & W7 & $832.3 \pm 191.9$ & & & & W7 & $802.5 \pm 446.0$ & & & \\
\hline \multirow{3}{*}{ 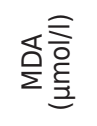 } & wo & $1.01 \pm 0.07$ & \multirow{3}{*}{-8.60} & \multirow{3}{*}{$0.003 *$} & \multirow{3}{*}{1.479} & wo & $0.97 \pm 0.05$ & \multirow{3}{*}{-6.83} & \multirow{3}{*}{$0.016 *$} & \multirow{3}{*}{1.838} \\
\hline & & & & & & & & & & \\
\hline & W7 & $0.92 \pm 0.05$ & & & & W7 & $0.90 \pm 0.02$ & & & \\
\hline \multirow{3}{*}{ 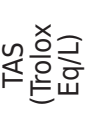 } & wo & $1.62 \pm 1.12$ & \multirow{3}{*}{-62.5} & \multirow{3}{*}{0.334} & \multirow{3}{*}{0.616} & wo & $1.08 \pm 1.16$ & \multirow{3}{*}{17.4} & \multirow{3}{*}{0.882} & \multirow{3}{*}{-0.081} \\
\hline & & & & & & & & & & \\
\hline & W7 & $0.92 \pm 1.15$ & & & & W7 & $118 \pm 1.30$ & & & \\
\hline \multirow{3}{*}{ 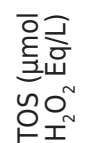 } & Wo & $4.96 \pm 0.59$ & \multirow{3}{*}{33.5} & \multirow{3}{*}{0.126} & \multirow{3}{*}{-0.998} & WO & $6.80 \pm 2.01 \#$ & \multirow{3}{*}{18.3} & \multirow{3}{*}{0.783} & \multirow{3}{*}{-0.166} \\
\hline & & & & & & & & & & \\
\hline & W7 & $6.52 \pm 2.13$ & & & & W7 & $7.28 \pm 3.54$ & & & \\
\hline
\end{tabular}

Note: ${ }^{*} p \leq 0.05, \# p=0.037$ (statistically significantly higher compared with data of CET); CET - continuous endurance training; SIT - sprint interval training; GSH-Px, glutathione peroxidase; MDA - malondialdehyde; TAS - total antioxidant status; TOS - total oxidant status; M - mean; SD - standard deviation; $\Delta \%$ - percentage change in means ( - : decrease); $d$, Cohen's d ( $<0.2$ trivial; $0.2 \leq d<0.5$ small; $0.5 \leq d<0.8$ moderate; $d \geq 0.8$ large effect size); $W$ - week.

\section{DISCUSSION}

The main contribution of the study is the result of a 7-week SIT in a marked reduction of MDA and TOS levels as oxidative stress markers and the elevated antioxidant status indices (TAS and GSH-Px level) with similar results that was noted for the CET group. Most importantly, these adaptations were achieved in only 21 exercise sessions with 52.30 min of pure exercise time and a total of 8.45-hour time commitment in the whole 7-week period, even though total active time spent for CET (14 hours) was fifteen times more than SIT. Therefore, the SIT modality may be preferred due to its greater time efficiency compared to CET. As a result, SIT may be accepted as a time-efficient strategy for achieving favorable oxidative stress and antioxidant adaptation.

Several studies in the literature have investigated the effects of exercise models of different intensities on oxidative stress and antioxidant status. However, while there is research on the acute effect of HIIT in healthy individuals [17, 29-31], studies showing the regular training effects of HIIT on oxidative stress and antioxidant status are scarce. Moreover, the use of different exercise models, a single sampling period of the studies, and the different measured oxidative stress and antioxidant status markers makes it difficult to compare the results of the previous investigations.

Previous research showed that the adaptation seen with increased activity of antioxidant enzymes is one of the fundamental changes in aerobic or anaerobic skeletal muscle. Thus, oxidative stress decreases, and lipid peroxidation levels attenuate [12, 32, 33]. Although the influence of oxidative stress on exercise performance is not apparent, inhibition of lipid peroxidation has been shown to be associated with reducing muscular fatigue and alleviating inflammation [34].

The elevated ROS levels produced during the high energy turnover rate required in the active muscle leads to increased lipid peroxidation, which is measured by the formation of MDA after a SIT session [12, 34], thus reducing membrane fluidity, permeability, and 
excitability, as well as altering membrane-bound enzyme functions [18]. With compelling evidence that exercise-induced increases in oxidative stress are adaptive, lipid peroxidation may stimulate adaptations such as structural remodeling of external cellular membranes and lipoproteins [35]. Training has been suggested to upregulate antioxidant enzyme levels in tissues that perform systematic exercise, and reduce resting lipid peroxidation [36]. It has been reported that eight weeks of continuous moderate-intensity training and high-intensity training in master runners may be sufficient for antioxidant systems to reduce the acute damage of each high-intensity training session [37]. A decrease in MDA was observed with the 12-week SIT training performed on rats. Although the mechanism behind the peroxidation reduction is unclear, it is suggested that an upregulation of GSHPx activity may be responsible. Due to its sensitivity to intracellular levels of reactive oxygen and its role in the destruction of the end products of oxidation (including lipid peroxides), GSH-Px may be the most important antioxidant enzyme for cell survival. An increase in GSH-Px may also contribute to the training adaptation during the study [38]. This interpretation may explain the results of the seven-week SIT and CET observations that revealed a similar decrease in MDA and a similar increase in TOS levels, reflecting the total amount of oxidant in the body.

To prevent exercise-induced oxidative stress, antioxidant defense systems including superoxide dismutase (SOD), catalase (CAT) and GPx enzymes, and non-enzymatic substances such as reduced glutathione (GSH), and vitamins A, C, and E, and selenium act in synergy. GSH, an important intracellular antioxidant, plays a prominent role in cellular defense against oxidative stress by directly removing reactive oxygen species and as a substrate for GSH-Px [32, 38]. The TAS level can be considered as a reliable biomarker reflecting the body's total antioxidant defense. Our study showed that SIT caused a more positive change in TAS and GSH-Px levels compared to CET. This result suggests that the CET group has low basal values, and intensity is more effective than the duration of the exercises. The increase in antioxidant system indicators has been interpreted that higher intensity exercise can promote more redox health benefits and help protect against chronic oxidative stress-related diseases [39].

In addition, the results of two other studies with healthy participants are in line with

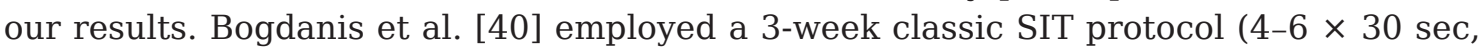
4 min rest) with eight healthy active men to investigate the oxidative stress markers. At the end of nine sessions of the SIT period, they observed that oxidative stress markers decreased (protein carbonyl and thiobarbituric acid reactive substances (TBARS)) while antioxidant capacity and CAT activity increased. Fisher et al. [23] implemented 90\% of the maximum anaerobic power (HIIT protocol), $4 \times 30$-sec loadings, and 4-min active rest with $15 \%$ of the maximum anaerobic power for a week to a group of eight healthy active men. Participants completed a total of 3 sessions at 48-hour intervals. Results demonstrated an increase in oxidative stress (plasma TBARS levels). Also, there were significant increases in SOD, CAT, and GPx activities in lymphocytes after HIIT. Although the antioxidant system improved as a result of repetition of similar high intensities in these studies, the reduction in oxidative stress markers observed at the end of 9 sessions did not occur at the end of the 3-session period.

The major limitation of the current study is the absence of control of the antioxidant content in the diet regimen of the participants. Therefore, the study results assume that each participant followed his regular daily diet regimen and did not take any supplements following the researcher's instructions. 


\section{CONCLUSIONS}

Besides its popularity among athletes and the general population, a study investigating the effects of regular SIT training on oxidative stress and antioxidant status with a comparison to CET could not be found in the scholarly literature. In this study, it is assumed that oxidant and antioxidant balance increases the effectiveness of the SIT exercise model for healthy and patient individuals with similar adaptations provided by short term SIT and CET.

\section{REFERENCES}

[1] Little JP, Safdar A, Wilkin GP, Tarnopolsky MA, Gibala MJ. A practical model of low-volume high-intensity interval training induces mitochondrial biogenesis in human skeletal muscle: potential mechanisms. J Physiol. 2010;588(Pt 6):1011-22. https:// doi.org/10.1113/jphysiol.2009.181743

[2] Donnelly JE, Blair SN, Jakicic JM, Manore MM, Rankin JW, Smith BK. American College of Sports Medicine Position Stand. Appropriate physical activity intervention strategies for weight loss and prevention of weight regain for adults. Med Sci Sports Exerc. 2009;41:459-471. https://doi.org/10.1249/MSS.0b013e3181949333

[3] Nybo L, Sundstrup E, Jakobsen MD, et al. High-intensity training versus traditional exercise interventions for promoting health. Med Sci Sports Exerc. 2010;42(10):1951-1958. https://doi.org/10.1249/MSS.0b013e3181d99203

[4] Bayati M, Farzad B, Gharakhaniou R, Agha-Alinejad H. A practical model of low-volume high-intensity interval training induces performance and metabolic adaptations that resemble 'all-out' sprint interval training. J Sports Sci Med. 2011;10:571-576.

[5] Gibala MJ, Little JP, Macdonald MJ, Hawley JA. Physiological adaptations to low-volume, high-intensity interval training in health and disease. J Physiol. 2012;590(Pt 5):1077-1084. https://doi.org/10.1113/jphysiol.2011.224725

[6] Burgomaster KA, Howarth KR, Phillips SM, et al. Similar metabolic adaptations during exercise after low volume sprint interval and traditional endurance training in humans. J Physiol. 2008;586(1):151-160. https://doi.org/10.1113/jphysiol.2007.142109

[7] Burgomaster KA, Heigenhauser GJ, Gibala MJ. Effect of short-term sprint interval training on human skeletal muscle carbohydrate metabolism during exercise and time-trial performance. J Appl Physiol (1985). 2006;100(6):2041-2047. https:// doi.org/10.1152/japplphysiol.01220.2005

[8] McCarty NP, Craighead DH, Freeberg KA. Overcoming exercise barriers: home-based HIT for reducing cardiovascular disease risk in obese individuals. J Physiol. 2020;598.1:13-14. https://doi.org/10.1113/JP279074

[9] Shiraev T, Barclay G. Evidence based exercise. Clinical benefits of high intensity interval training. Aust Fam Physician. 2012;41(12):960-962.

[10] Freese EC, Gist NH, Cureton KJ. Physiological responses to an acute bout of sprint interval cycling. J Strength Cond Res. 2013;27(10):2768-2773. https://doi.org/10.1519/JSC.0b013e318281575c

[11] Radak Z, Chung HY, Koltai E, Taylor AW, Goto S. Exercise, oxidative stress and hormesis. Ageing Res Rev. 2008;7(1):34-42. https://doi.org/10.1016/j.arr.2007.04.004

[12] Ascensão A, Rebelo A, Oliveira E, Marques F, Pereira L, Magalhães J. Biochemical impact of a soccer match - Analysis of oxidative stress and muscle damage markers throughout recovery. Clin Biochem. 2008;41(10-11):841-851. https://doi. org/10.1016/j.clinbiochem.2008.04.008

[13] Reid MB. Free Radicals and Muscle Fatigue: Of ROS, Canaries, and the IOC. Free Radic Biol Med. 2008;44(2):169-179. https:// doi.org/10.1016/j.freeradbiomed.2007.03.002

[14] Parolin ML, Chesley A, Matsos MP, Spriet LL, Jones NL, Heigenhauser GJF. Regulation of skeletal muscle glycogen phosphorylase and PDH during maximal intermittent exercise. Am J Physiol. 1999;277:E890-E900. https://doi.org/10.1152/ ajpendo.1999.277.5.E890

[15] Daussin FN, Zoll J, Dufour SP, et al. Effect of interval versus continuous training on cardiorespiratory and mitochondrial functions: relationship to aerobic performance improvements in sedentary subjects. Am J Physiol Regul Integr Comp Physiol. 2008;295:R264-R272. https://doi.org/10.1152/ajpregu.00875.2007

[16] Vollaard NB, Shearman JP, Cooper CE. Exercise-induced oxidative stress: Myths, realities and physiological relevance. Sports Med. 2005;35:1045-1062. https://doi.org/10.2165/00007256-200535120-00004

[17] Cuevas MJ, Almar M, García-Glez JC, et al. Changes in oxidative stress markers and NF-kappa B activation induced by sprint exercise. Free Radic Res. 2005;39(4):431-439. https://doi.org/10.1080/10715760500072149

[18] Bloomer RJ, Goldfarb AH. Anaerobic exercise and oxidative stress: a review. Can J Appl Physiol. 2004;29(3):245-263. https:// doi.org/10.1139/h04-017

[19] Sloth M, Sloth D, Ovengaard K, Dalgas U. Effects of sprint interval training on $\mathrm{VO}_{2}$ max and aerobic exercise performance: A systematic review and meta-analysis. Scand J Sci Sports. 2013;23(6):e341-352. https://doi.org/10.1111/sms.12092

[20] Matsuo T, Saotome K, Seino S, et al. Effects of a low-volume aerobic-type interval exercise on $\mathrm{VO}_{2}$ max and cardiac mass. Med Sci Sports Exerc. 2014;46(1):42-50. https://doi.org/10.1249/MSS.0b013e3182a38da8

[21] O'Donovan G, Owen A, Bird SR, et al. Changes in cardiorespiratory fitness and coronary heart disease risk factors following 24 wk of moderate- or high-intensity exercise of equal energy cost. J Appl Physiol. 2005;98:1619-1625. https://doi.org/10.1152/ japplphysiol.01310.2004

[22] Stepto NK, Martin DT, Fallon KE, Hawley JA. Metabolic demands of intense aerobic interval training in competitive cyclists. Med Sci Sports Exerc. 2001;33(2):303-310. https://doi.org/10.1097/00005768-200102000-00021

[23] Fisher G, Schwartz DD, Quindry J, et al. Lymphocyte enzymatic antioxidant responses to oxidative stress following high-intensity interval exercise. J Appl Physiol (1985). 2011;110(3):730-737. https://doi.org/10.1152/japplphysiol.00575.2010

[24] Rudarli Nalcakan G. The effects of sprint interval vs. continuous endurance training on physiological and metabolic adaptations in young healthy adults. J Hum Kinet. 2014;44:97-109. https://doi.org/10.2478/hukin-2014-0115 
[25] Ohkawa H, Ohishi N, Yagi K. Assay for lipid peroxides in animal tissues by thiobarbituric acid reaction. Anal Biochem. 1979;95(2):351-358. https://doi.org/10.1016/0003-2697(79)90738-3

[26] Paglia DE, Valentine WN. Studies on the quantitative and qualitative characterization of erythrocyte glutathione peroxidase J Lab Clin Med. 1967;70(1):158-169.

[27] Erel O. A novel automated direct measurement method for total antioxidant capacity using a new generation, more stable ABTS radical cation. Clin Biochem. 2004;37:277-285. https://doi.org/10.1016/j.clinbiochem.2003.11.015

[28] Erel O. A new automated colorimetric method for measuring total oxidant status. Clin Biochem. 2005;38:1103-1111. https:// doi.org/10.1016/j.clinbiochem.2005.08.008

[29] Bloomer RJ, Falvo MJ, Fry AC, Schilling BK, Smith WA, Moore CA. Oxidative stress response in trained men following repeated squats or sprints. Med Sci Sports Exerc. 2006;38(8):1436-1442. https://doi.org/10.1249/01.mss.0000227408.91474.77

[30] Deminice R, Trindade CS, Degiovanni GC, et al. Oxidative stress biomarkers response to high intensity interval training and relation to performance in competitive swimmers. J Sports Med Phys Fitness. 2010;50(3):356-362.

[31] Farney TM, McCarthy CG, Canale RE, Schilling BK, Whitehead PN, Bloomer RJ. Absence of blood oxidative stress in trained men after strenuous exercise. Med Sci Sports Exerc. 2012;44(10):1855-1863. https://doi.org/10.1249/MSS.0b013e3182592575

[32] Pingitore A, Lima GP, Mastorci F, Quinones A, Iervasi G, Vassalle C. Exercise and oxidative stress: potential effects of antioxidant dietary strategies in sports. Nutrition. 2015;31(7-8):916-922. https://doi.org/10.1016/j.nut.2015.02.005

[33] Zwetsloot KA, Nieman DC, Knab A, et al. Effect of 4 weeks of high-intensity interval training on exercise performance and markers of inflammation and oxidative stress. FASEB J. 2017;31(1supplement):839.1.

[34] Shing CM, Peake JM, Ahern SM, et al. The effect of consecutive days of exercise on markers of oxidative stress. Appl Physiol Nutr Metab. 2007;32(4):677-685. https://doi.org/10.1139/H07-051

[35] Wadley AJ, Chen YW, Lip GY, Fisher JP, Aldred S. Low volume-high intensity interval exercise elicits antioxidant and antiinflammatory effects in humans. J Sports Sci. 2016;34(1):1-9. https://doi.org/10.1080/02640414.2015.1035666

[36] Bloomer RJ, Fisher-Wellman KH. Blood oxidative stress biomarkers: influence of sex, exercise training status, and dietary intake. Gend Med. 2008;5(3):218-228. https://doi.org/10.1016/j.genm.2008.07.002

[37] Vezzoli A, Pugliese L, Marzorati M, Serpiello FR, La Torre A, Porcelli S. Time-course changes of oxidative stress response to highintensity discontinuous training versus moderate-intensity continuous training in masters runners. PLoS One. 2014;9(1):e87506. https://doi.org/10.1371/journal.pone.0087506

[38] Cunningham P, Geary M, Harper R, Pendleton A, Stover S. High intensity sprint training reduces lipid peroxidation in fasttwitch skeletal muscle. JEP online. 2005;8(6):18-25.

[39] Parker L, McGuckin TA, Leicht AS. Influence of exercise intensity on systemic oxidative stress and antioxidant capacity. Clin Physiol Funct Imaging. 2014;34(5):377-383. https://doi.org/10.1111/cpf.12108

[40] Bogdanis GC, Stavrinou P, Fatouros IG, et al. Short-term high-intensity interval exercise training attenuates oxidative stress responses and improves antioxidant status in healthy humans. Food Chem Toxicol. 2013;61:171-177. https://doi.org/10.1016/j . fct.2013.05.046 